\title{
Hypoxia enhances self-renewal properties and markers of mesenchymal stem cells
}

\author{
Vivi Yustianingsih*, Titiek Sumarawati**, and Agung Putra ${ }^{* * *}, \dagger$
}

\section{ABSTRACT}

\section{BACKGROUND}

Mesenchymal stem cells (MSCs) are multipotent stromal cells that express CD73, CD90, and CD105 surface markers, but not CD14, CD45, CD34,CD11b, and HLA-DR. MSCs under hypoxic conditions have the essential role of maintaining the stemness capacity by releasing several growth factors into their medium, known as hypoxia conditioned medium (HCM). This study was performed to compare the effect of percentage of HCM to normoxic medium (NM) in increasing MSC proliferation marked by proliferation rate and surface marker expression.

\section{METHODS}

This study was of post-test only control group design using human umbilical cord-MSCs (hUC-MSCs) as subjects. The HCM treatment group was obtained by culturing MSCs under $5 \% \mathrm{O}_{2}$, whereas the NM control group was grown under $20 \% \mathrm{O}_{2}$. The hUC-MSCs were divided into 4 groups with different dose ratios of HCM to NM (25\%:75\%; $50 \%: 50 \% ; 75 \%: 25 \%$ for P1, P2 and P3, respectively and $100 \%$ of NM for the controls). All of these groups were maintained at $37^{\circ} \mathrm{C}$ and the data was collected after 72 hours incubation. MSC marker expression of CD73, CD90 and CD105 was analyzed using flow cytometry and MSC proliferation by trypan blue assay.

\section{RESULT}

There were significant differences in MSC marker expression of CD73, $\mathrm{CD} 90$ and CD105 and proliferation at all dose ratios of $\mathrm{HCM}$ to $\mathrm{NM}(\mathrm{p}<0.05)$.

\section{CONCLUSION}

Low oxygen concentration promotes MSC proliferation and stemness thus it might be beneficial for maintaining the MSC physiologic niche in-vitro.

Keywords: MSC, MSC-HCM, proliferation, stemness
*Postgraduate Biomedical Science Program, Medical Faculty,

Sultan Agung Islamic University,

Semarang, Indonesia **Department of Postgraduate Biomedical Science, Medical Faculty, Sultan Agung Islamic University, Semarang, Indonesia ***Department of Pathological Anatomy, Medical Faculty, Sultan Agung Islamic University, Semarang Indonesia $\uparrow$ Stem Cell and Cancer Research Laboratory, Medical Faculty, Sultan Agung Islamic University

\section{Correspondence}

Dr. dr. H. Agung Putra, M. Si. Med. Chairman of Stem Cell and Cancer Research (SCCR) Laboratory, Medical Faculty, Universitas Islam Sultan Agung Semarang, J1. Raya Kaligawe KM. 4 Semarang, Jawa Tengah 50112

Phone.+628164251646

Email: dr.agungptr@gmail.com ORCID ID : 0000-0003-4261-9437

Date of first submission, October 10 , 2018

Date of final revised submission,

October 11, 2019

Date of acceptance, October 16, 2019

This open access article is distributed under a Creative Commons AttributionNon Commercial-Share Alike 4.0 International License

Cite this article as: Yustianingsih V, Sumarawati T, Putra A. Hypoxia enhances self-renewal properties and markers of mesenchymal stem cells. UnivMed 2019;38:164-71. doi: 10.18051/ UnivMed.2019.v38.164-171 


\section{INTRODUCTION}

Mesenchymal stem cells (MSCs) are multipotent stromal cells with the capacity for selfrenewal and differentiation into mesodermal lineages such as chondrocytes, osteoblasts, adipocytes, and neurons. ${ }^{(1)}$ According to the International Society for Cellular Therapy (ISCT) MSCs' main characteristics are adherence to plastic, expression of CD73, CD90, and CD105 and lack of expression of CD14, CD45, CD34, CD11b, and CD31 and HLA-DR. ${ }^{(2)}$ Mesenchymal stem cells have been widely used for tissue engineering and treatment of degenerative diseases and immune disorders, due to their trophic activity, immunomodulatory and angiogenic properties and multipotent differentiation capacity. ${ }^{(3)}$

Mesenchymal stem cells can be isolated from a wide range of source tissues such as the umbilical cord, bone marrow, adipose tissue and dental pulp. ${ }^{(4-6)}$ Moreover, an essential goal for expansion of MSCs in vitro is to obtain sufficient cell numbers for research and clinical application. This depends mainly on tissue source of MSCs and processing method. In umbilical cord-derived MSCs (UC-MSCs) the stemness is highest in comparison with bone marrow and adiposederived MSCs, due in part to their higher telomerase activity, and pluripotent properties under certain conditions. ${ }^{(7-9)}$ A previous study has shown that the major concerns of in vitro MSC propagation are poor growth kinetics, early senescence and DNA damage during expansion. ${ }^{(6)}$ Therefore, isolation techniques, culture medium, oxygen tension, supplements, cell seeding density and their modification such as under hypoxia and TNF- $\alpha$ are essential for MSC propagation. $^{(10,11)}$

One previous study reported that oxygen concentration is a critical environmental factor for maintaining in vitro stem cell plasticity and proliferation. ${ }^{(12)}$ Other studies also demonstrated that hypoxic conditions $\left(\mathrm{O}_{2}\right.$ pressure under $5 \%$ have positive effects on MSCs in terms of in vitro survival and self-renewal, particularly in preserving the stemness and enhancing proliferation. ${ }^{(13-15)}$ There was an enhancement of MSC proliferation in hypoxic conditions compared to normoxia even following 2 weeks of incubation of the cultures. ${ }^{(16)}$ However, this study did not report the use of the hypoxia chamber as a culture device. In contrast, another study reported that continued hypoxia reduced the clonogenic ability and differentiation potential of MSCs. ${ }^{(7)}$ Another study described that 24-h hypoxia is beneficial for the functional properties of MSCs. ${ }^{(17)}$

Since hypoxia is the most similar to the physiological conditions occurring in living organisms, we decided to examine MSC culture both in normoxic and hypoxic conditions. In this study, we analyzed the comparative effect of hypoxia-conditioned medium (HCM) obtained after 24-h hypoxia incubation to NM (with HCM:NM ratios of about 25\%:75\%; 50\%:50\% and 75\%:25\%, respectively) in enhancing MSC stemness through analyzing MSC proliferation and CD73, CD90 and CD105 expression for 72 hours incubation.

\section{METHODS}

\section{Research design}

This post-test only control group design was conducted in the Stem Cell and Cancer Research Laboratory, Faculty of Medicine, Universitas Islam Sultan Agung (Unissula), Semarang from July-September 2018.

\section{Research subjects}

Human umbilical cord-MSCs (hUC-MSC) were used as the subjects and divided into 4 groups with different doses of MSC-HCM. The total number of hUC-MSCs was $1.2 \times 10^{6}$ cells and was equally divided into 4 groups. The control group was treated with normal medium, whereas the treatment groups were supplemented with $25 \%$ $\mathrm{HCM}(\mathrm{P} 1), 50 \% \mathrm{HCM}(\mathrm{P} 2)$ and $75 \% \mathrm{HCM}(\mathrm{P} 3)$, respectively.

\section{Mesenchymal stem cell isolation}

Mononuclear cells (MNCs) from an umbilical cord were collected and separated by 
Ficoll-Paque solution (density $1.077 \mathrm{~g} / \mathrm{mL}$; GE) in centrifuge tubes $(15 \mathrm{~mL})$. The mononuclear cells were transferred to a new tube and washed twice through centrifugation at $2000 \mathrm{rpm}$ for 10 minutes. They were then seeded into $25-\mathrm{cm}^{2}$ flasks at a density of $1 \times 10^{7}-10^{8}$ cells $/ \mathrm{cm}^{2}$. The flasks contained Dulbecco's modified Eagle's MediumLow Glucose (DMEM-LG, GIBCO Invitrogen) supplemented with $1 \%$ L-Glutamine $200 \mathrm{mM}, 1 \%$ Antibiotic-Antimycotic comprising $10.000 \mathrm{U} / \mathrm{mL}$ sodium penicillin, $1 \% 10.000 \mu \mathrm{g} / \mathrm{mL}$ streptomycin sulfate, $25 \mu \mathrm{g} / \mathrm{mL}$ amphotericin B (GIBCO/ Invitrogen Corporation), and 10\% Fetal Bovine Serum (GIBCO/Invitrogen Corporation). Umbilical cord blood (UCB)-MSC cultures were maintained at $37{ }^{\circ} \mathrm{C}$ in $5 \% \mathrm{CO}_{2}$ and non-adherent cells were removed after $48 \mathrm{~h}$. The medium was changed every other day. The experiments were performed at the fourth passage of the cultures with approximately $80-90 \%$ confluence. UCBMSC lineages were established in culture up to the fourth passage.

\section{Characterization of MSCs}

The characteristics of MSCs were analyzed by flow cytometric analysis at the fourth passage. The cells were subsequently incubated at room temperature and in the dark with fluorescein isothiocyanate (FITC)conjugated, allophycocyanin (APC)-conjugated or phycoerythrin (PE)-conjugated monoclonal antibodies, including CD73, CD90 and CD105. APC-, PE-, and FITC-conjugated isotypes were used as negative controls. The analysis used BD Pharmingen $^{\mathrm{TM}}$ (BD Biosciences, Franklin Lakes, NJ, USA) at $4{ }^{\circ} \mathrm{C}$ for $30 \mathrm{~min}$. The cells were washed twice with $1 \% \mathrm{BSA} / \mathrm{PBS}$, resuspended in $200 \mu \mathrm{L} 1 \% \mathrm{BSA} / \mathrm{PBS}$ and analyzed using a flow cytometer (BD Biosciences, San Jose, CA, USA).

\section{In-vitro differentiation}

For the differentiation test, MSCs were grown on 24-well plates at densities of $1 \times 10^{4}$ cells/ well, with DMEM supplemented with osteogenicinduction medium containing $10^{-7} \mathrm{~mol} / \mathrm{L} / 0.1 \mu \mathrm{M}$ dexamethasone, $10 \mathrm{mmol} / \mathrm{L} \beta$-glycerophosphate, $50 \mu \mathrm{mol} / \mathrm{L}$ ascorbate-2-phosphate (Sigma-Aldrich, Louis St, MO) and 10\% fetal bovine serum (FBS). The cells were rinsed in PBS and fixed with cold $70 \%$ ethanol $(\mathrm{v} / \mathrm{v})$ for 1 hour at room temperature, then rinsed three times with twicedistilled water after 21 days of induction. A volume of $1 \mathrm{ml} 2 \%$ Alizarin Red solution (w/v) ( $\mathrm{pH} 4.1$ 4.3) was added and the cells incubated for 30 minutes at room temperature, then rinsed four times in twice-distilled water.

\section{Hypoxia conditioned medium (HCM)}

A previous protocol ${ }^{(18)}$ was adapted for use in this study. Briefly, hMSCs were incubated until confluent, after which they were seeded in a T 25 flask $\left(2 \times 10^{6}\right.$ cells $)$, washed twice with endothelial basal medium (EBM-2; Lonza), and then placed in a hypoxic chamber (Anaerobic Environment; ThermoForma, Waltham, MA, USA) containing $5 \mathrm{ml}$ EBM-2 for 12 hours. The airtight humidified hypoxic chamber was maintained at $37^{\circ} \mathrm{C}$ and continuously supplied with $5 \% \mathrm{CO}_{2}, 10 \% \mathrm{H}_{2}$, and $85 \% \mathrm{~N}_{2}$. The oxygen level in the chamber was $\sim 0.5 \%$. After incubation, the medium was collected and centrifuged at $1000 \mathrm{rpm}$ for 10 minutes at $4{ }^{\circ} \mathrm{C}$. Then the HCM was added to the treatment groups at concentrations of $25,50 \%$ and $75 \%$, respectively.

\section{Mesenchymal stem cell proliferation essay and stemness}

The cells were counted in a hemocytometer for analyzing cell proliferation. In brief, following treatment, the cells are harvested and an aliquot of cells is combined with trypan blue dye solution and loaded into the hemocytometer chamber. The cells are then viewed under the microscope and the number of live cells present within a specific area are counted. The number of cells counted per area multiplied by the dilution factor will determine the number of live cells per milliliter. The stemness of MSCs was analyzed after 72-h induction using a BD Pharmingen ${ }^{\mathrm{TM}}$ flow cytometer (BD Biosciences, Franklin Lakes, NJ, USA). 


\section{Statistical analysis}

All values are expressed as the mean $\pm \mathrm{SD}$. Comparisons between the four groups were analyzed using ANOVA and then followed by posthoc Fisher's LSD. A p value of $<0.05$ was considered significant. All analyses were performed with SPSS 16.0.

\section{Ethical clearance}

All research activities were approved by the Commission on Test Animal Ethics (Komisi Etik Hewan Uji), Faculty of Medicine, Universitas Islam Sultan Agung, Semarang, under No. 233/ VII/2018/Komisi Bioetik.

\section{RESULTS}

\section{Mesenchymal stem cell characterization}

The MSCs were successfully isolated from the umbilical cord, based on their adherence to plastic. After reaching $80 \%$ confluence, the cells were harvested for 4 passages. The MSCs showed a fusiform appearance, became confluent after 5-7 days in culture and were regularly passaged. Flow cytometry analysis showed that the MSCs were positively expressing $75.8 \%$ of CD73, $84.1 \%$ of CD90 and $55.2 \%$ of CD 105 (Figure 1).
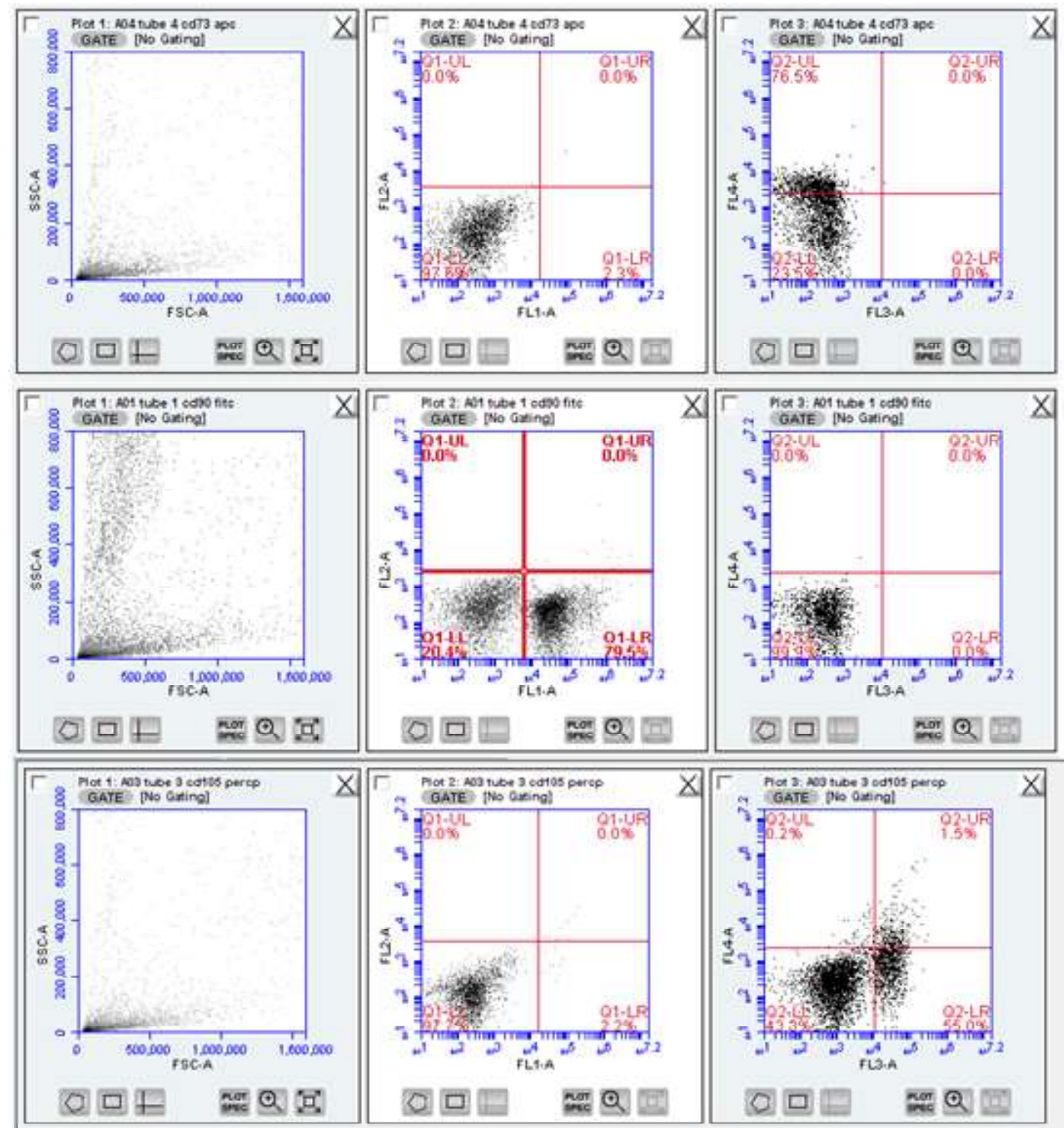

Figure 1. Characteristics of UC-MSCs expressing CD73, CD90 and CD105 by flow cytometry 

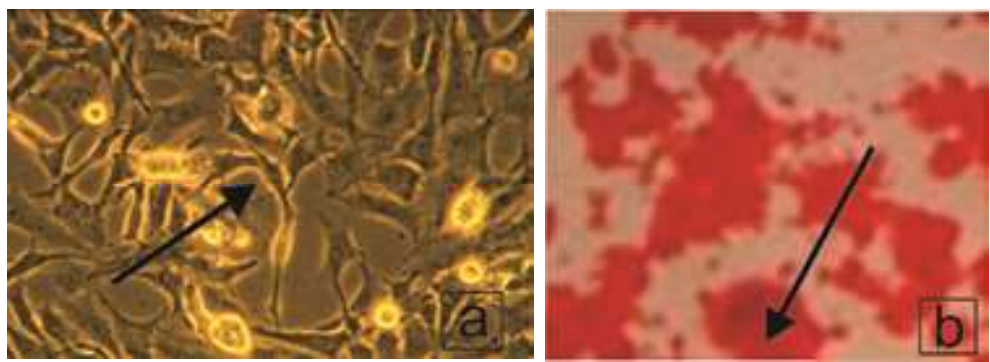

Figure 2. (a) UC-MSC-like from in vitro culture showing fibroblast-like and polygonal cells, at 40x magnification, (b) osteogenic differentiation test with Alizarin Red staining appearing in MSC population

\section{In vitro differentiation}

The MSC differentiation assay was done by means of osteogenic medium. The results showed that MSCs were capable of differentiating into osteogenic cells as indicated by their red color from Alizarin red staining (Figure 2b).

\section{MSCs self-renewal and stemness}

The MSC appearance was analyzed using the light microscope at 24, 48, and 72 hours after MSC-HCM induction (Figure 3). The results showed significant between-group differences in MSC self-renewal appearance $(\mathrm{p}=0.000)$. The highest result was shown by $\mathrm{P} 3$ with a high concenteration of MSC-HCM (75\%) (Table 1). This is in line with the expression of MSC positive markers (CD 73, CD90, CD105).

\section{DISCUSSION}

Several studies have reported that hypoxic conditions may modulate the paracrine activity of MSCs by up-regulating the various secretable factors into a medium such as HCM. These soluble molecules are associated with the

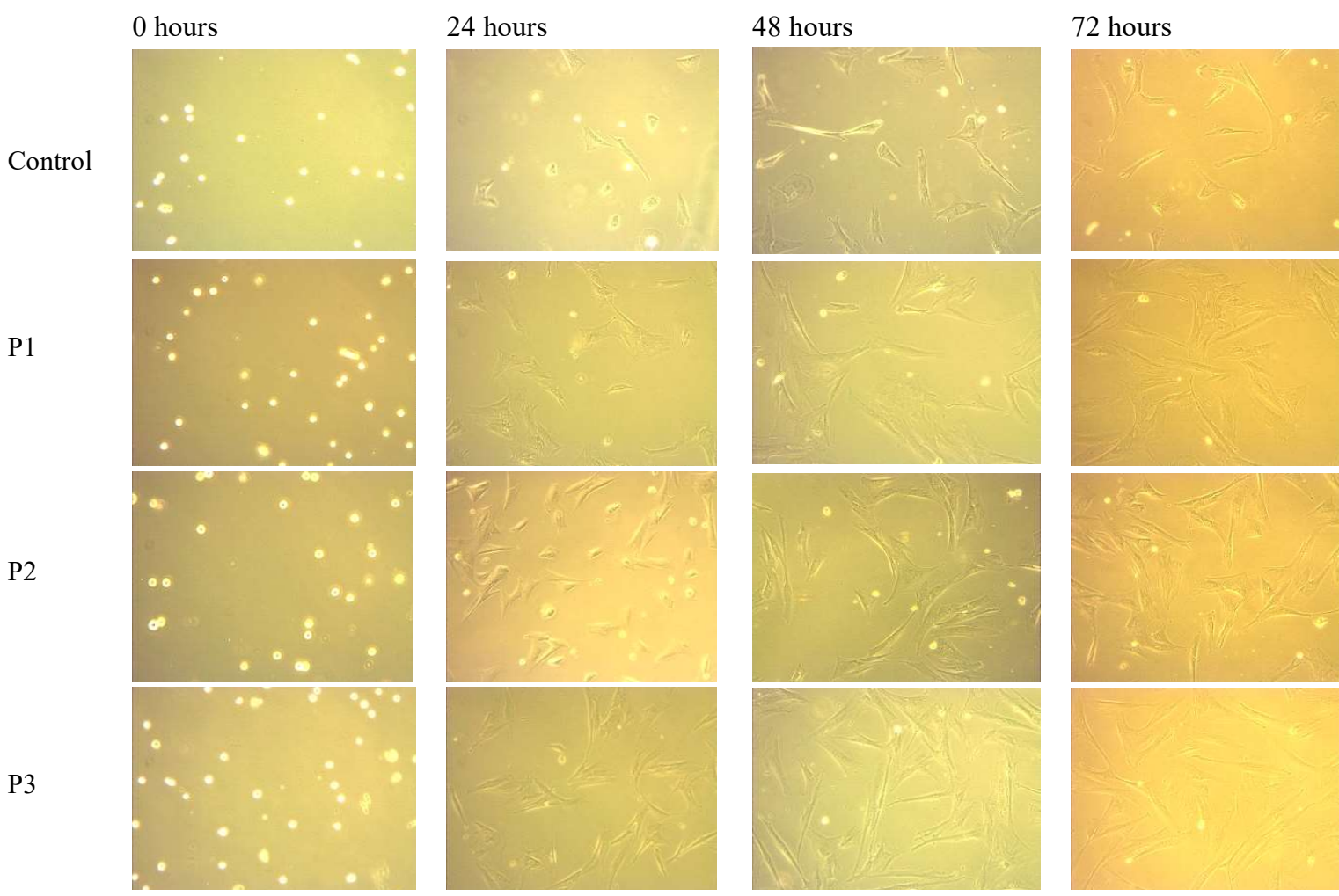

Figure 3. Appearance under light microscope of MSCs after HCM induction 
Table 1. Distribution of MSC proliferation and stemness after 72 hour incubation by treatment groups

\begin{tabular}{lccccc}
\hline \multirow{2}{*}{ Variable } & \multicolumn{4}{c}{ Treatment groups } & \multirow{2}{*}{ p value } \\
\cline { 2 - 5 } & Control (n=3) & P1 (n=3) & P2 (n=3) & P3 (n=3) & \\
\hline Proliferation (cell) & $411666.67 \pm$ & $461666.67 \pm$ & $535000.00 \pm$ & $571666.67 \pm$ & $0.000^{*}$ \\
CD73 (\%) & 12583.05 & 10408.33 & 13228.75 & 10606.60 & $0.000^{*}$ \\
CD90 (\%) & $76.41 \pm 0.70$ & $86.5 \pm 1.20$ & $90.86 \pm 0.40$ & $99.26 \pm 0.50$ & $0.000^{*}$ \\
CD105 (\%) & $84.16 \pm 0.30$ & $90.83 \pm 0.45$ & $93.73 \pm 0.45$ & $96.43 \pm 0.55$ & $0.000^{*}$ \\
\hline
\end{tabular}

Note: P1 medium with 25\% HCM, P2 medium with 50\% HCM, P3 medium with 75\% HCM. "Significant at p $<0.05$

increased proliferation rate and stemness properties of MSCs. Whereas the effects of hypoxia have been investigated previously, the comparison between HCM and NM in enhancing MSC proliferation in vitro by constantly maintaining stemness properties remains unknown. In this study we introduced various HCM to NM dose ratios in MSCs using the hypoxic condition chamber as in a previous study, ${ }^{(17)}$ then analyzed the increase in MSC proliferation rate and their expression of CD73, CD90, and CD105.

Our results showed that there were significant differences between all HCM to NM dose ratios in cell proliferation rate after 72 hours. This is in accordance with a previous study that found that hypoxic conditions may increase the proliferation and stemness in MSCs. ${ }^{(18)} \mathrm{We}$ suggest that the hypoxic state induces hypoxiainducible factor-1a (HIF-1a) as transcription factor for inducing HIF-1a survival target genes including self-renewal and proliferation. ${ }^{(19)}$ This is in line with one other study reporting that MSCs under hypoxic conditions also have the ability to express the transcription embryonic factors such as Sox2. ${ }^{(18)}$

In undifferentiated mouse and human embryonic stem cells (ES), Oct3/4 and Sox 2 also interact with the Nanog promoter to strengthen the stemness of the cells. ${ }^{(18,20)}$ These factors serve as candidate molecules for mastering the regulation of initiation, maintenance, and differentiation of pluripotent cells. This is also in accordance with our finding that there are significant differences between all HCM to NM dose ratios in MSC positive markers (CD73,
CD90, CD105) with the highest result in group P3 (75\%:25\%). We suggest that the secretome released by MSCs under hypoxic conditions may induce the in vitro MSC progeny cells to grow over with maintaining their stemness.

Table 2. Multiple comparisons of MSC proliferation and stemness

\begin{tabular}{lcc}
\hline Groups & Mean differences & p value \\
\hline Proliferation & & \\
Control P1 & -50000.00 & 0.001 \\
P2 & -123333.33 & 0.000 \\
P3 & -155833.33 & 0.000 \\
P1 P2 & -73333.33 & 0.000 \\
P3 & -105833.33 & 0.000 \\
P2 P3 & -32500.00 & 0.020 \\
& & \\
CD73 & & \\
Control P1 & -10.033 & 0.000 \\
P2 & -14.43 & 0.000 \\
P3 & -22.83 & 0.000 \\
P1 P2 & -4.40 & 0.000 \\
P3 & -12.80 & 0.000 \\
P2 P3 & -8.40 & 0.000 \\
& & \\
CD90 & & \\
Control P1 & -6.66 & 0.000 \\
P2 & -9.56 & 0.000 \\
P3 & -12.26 & 0.000 \\
P1 P2 & -2.90 & 0.000 \\
P3 & -5.60 & 0.000 \\
P2 P3 & -2.70 & 0.000 \\
CD105 & & \\
Control P1 & -5.40 & 0.000 \\
P2 & -8.46 & 0.000 \\
P3 & -11.40 & 0.000 \\
P1 P2 & -3.06 & 0.000 \\
P3 & -6.00 & 0.000 \\
P2 P3 & -2.93 & 0.000 \\
\hline
\end{tabular}

Note: P1 medium with 25\% HCM, P2 medium with 50\% HCM, P3 medium with 75\% HCM 
Our findings indicate that HCM plays an important role in stemness potentials of the adult stem cell (ASC) including UC-MSC under hypoxic conditions. The limitation of this study is that we did not analyze the transcription marker molecules such as Sox 2 , Oct $3 / 4$ and Nanog.

\section{CONCLUSIONS}

Low oxygen concentration in MSCs promotes cell proliferation and stemness, thus it might be beneficial for maintaining the MSC physiologic niche in-vitro.

\section{CONFLICT OF INTEREST}

Competing interests: No relevant disclosures.

\section{ACKNOWLEDGEMENT}

We would like to thank the Stem Cell and Cancer Research Laboratory, Medical Faculty, Universitas Islam Sultan Agung, Semarang and the Department of Postgraduate Biomedical Science, Medical Faculty, Universitas Islam Sultan Agung, Semarang for all the facilities needed to finish this research.

\section{CONTRIBUTORS}

VY, AP and TS contributed to the basic concept and design of the study. VY and AP contributed to writing the manuscript and performing the experiment. VY and AP contributed to sample preparation and data collection. VY contributed to the statistical analysis. All authors have read and approved the final manuscript.

\section{REFERENCES}

1. Kagami H, Agata H, Tojo A. Bone marrow stromal cells (bone marrow-derived multipotent mesenchymal stromal cells) for bone tissue engineering: basic science to clinical translation.
Int J Biochem Cell Biol 2011;43:286-9. DOI: https:/ /doi.org/10.1016/j.biocel.2010.12.006.

2. Sharma A, Rani R. Do we really need to differentiate mesenchymal stem cells into insulinproducing cells for attenuation of the autoimmune responses in type 1 diabetes: immunoprophylactic effects of precursors to insulin-producing cells. Stem Cell Res Ther 2017;8:167. doi: 10.1186/s13287-017-0615-1.

3. Govindasamy V, Ronald VS, Abdullah AN, et al. Differentiation of dental pulp stem cells into isletlike aggregates. J Dent Res 2011;90:646-52. doi: 10.1177/0022034510396879.

4. Lund P, Pilgaard L, Duroux M, et al. Effect of growth media and serum replacements on the proliferation and differentiation of adiposederived stem cells. Cytotherapy 2009;11:189-97. doi: 10.1080/14653240902736266.

5. Hsieh JY, Fu YS, Chang SJ, et al. Functional module analysis reveals differential osteogenic and stemness potentials in human mesenchymal stem cells from bone marrow and Wharton's jelly of the umbilical cord. Stem Cells Dev 2010;19:1895910. https://doi.org/10.1089/scd.2009.0485.

6. Estrada JC, Albo C, Benguría A, et al. Culture of human mesenchymal stem cells at low oxygen tension improves growth and genetic stability by activating glycolysis. Cell Death Differ 2012;19:743-55. doi: 10.1038/cdd.2011.172.

7. Pattappa G, Thorpe SD, Jegard NC, et al. Continuous and uninterrupted oxygen tension influences the colony formation and oxidative metabolism of human mesenchymal stem cells. Tissue Eng Part C Methods 2013;19:68-79. doi: 10.1089/ten.TEC.2011.0734.

8. Haque N, Abu Kasim NH, Rahman MT. Optimization of pre-transplantation conditions to enhance the efficacy of mesenchymal stem cells. Int J Biol Sci. 2015;11:324-34. doi: 10.7150/ ijbs.10567.

9. Putra A, Ridwan FB, Putridewi AI, et al. The role of TNF- $\alpha$ induced MSCs on suppressive inflammation by increasing TGF- $\beta$ and IL-10. Open Access Maced J Med Sci 2018;6:1779-83. doi: 10.3889/oamjms.2018.404.

10. Ma T, Grayson WL, Fröhlich M, et al. Hypoxia and stem cell-based engineering of mesenchymal tissues. Biotechnol Prog 2009;25:32-42. doi: 10.1002/btpr.128.

11. Ahmed NEB, Murakami M, Kaneko S. The effects of hypoxia on the stemness properties of human dental pulp stem cells (DPSCs). Sci Rep 2016;6:35476. doi: 10.1038/srep35476.

12. Yamamoto Y, Fujita M, Tanaka Y, et al. Low oxygen tension enhances proliferation and maintains stemness of adipose tissue-derived stromal cells. 
Biores Open Access 2013;2:199-205. doi: 10.1089/ biores.2013.0004.

13. Putra A, Pertiwi D, Milla MN, et al. Hypoxiapreconditioned MSCs have superior effect in ameliorating renal function on acute renal failure animal model. Open Access Maced J Med Sci 2019;7:305-10. doi: 10.3889/oamjms.2019.049.

14. An HY, Shin HS, Choi JS, et al. Adipose mesenchymal stem cell secretome modulated in hypoxia for remodeling of radiation-induced salivary gland damage. PLoS One 2015;10:1-17. doi: 10.1371/journal.pone.0141862.

15. Mas-Bargues C, Sanz-Ros J, Román-Domínguez A, et al. Relevance of oxygen concentration in stem cell culture for regenerative medicine. Int $\mathrm{J}$ Mol Sci2019;20:1195. doi: 10.3390/ijms20051195.

16. Caroti CM, Ahn H, Salazar HF, et al. A novel technique for accelerated culture of murine mesenchymal stem cells that allows for sustained multipotency. Sci Rep 2017;7:13334. doi: 10.1038/ s41598-017-13477-y.
17. Lee SC, Jeong HJ, Lee SK, et al. Hypoxic conditioned medium from human adipose-derived stem cells promotes mouse liver regeneration through JAK/STAT3 signaling. Stem Cells Transl Med 2016;5:816-25. doi: 10.5966/sctm.2015-0191.

18. Fotia C, Massa A, Boriani F, et al. Hypoxia enhances proliferation and stemness of human adipose-derived mesenchymal stem cells. Cytotechnology 2015;67:1073-1084. doi: 10.1007/ s10616-014-9731-2.

19. Dengler VL, Galbraith M, Espinosa JM. Transcriptional egulation by hypoxia inducible factors. Crit Rev Biochem Mol Biol 2014;49:1-15. doi: 10.3109/10409238.2013.838205.

20. Shi G, Jin Y. Role of Oct4 in maintaining and regaining stem cell pluripotency. Stem Cell Res Ther 2010;1:39. doi: 10.1186/scrt39. 